\title{
School Librarians and Educational Leadership: Productive Pedagogy for the Information Age School
}

\author{
Dr Ross J. TODD, Director of Research, \\ Center for International Scholarship in School Libraries (CISSL), \\ School of Communication, Information and Library Studies, Rutgers, \\ The State University of New Jersey, USA.
}

\begin{abstract}
Against a backdrop of emerging paradigms of educational leadership, this research paper will explore and elaborate some of the fundamental dimensions of quality teaching and learning in information age schools based on the framework of Productive Pedagogy, and in the context of instructional interventions of school librarians in partnership with classroom teachers. This exploration is based on an analysis of extensive data collected during an extended school librarian-classroom teacher collaboration at Gill St Bernards' School Gladstone, N.J. in 2003-2004. Underpinning productive pedagogy is the belief that high quality teaching and learning should be the focus of professional learning communities and all stakeholders in the school environment. This paper overviews the significant findings of this study, with particular emphasis on an elucidation of the dimensions of productive pedagogy that have enabled students to learn successfully in this collaborative inquiry learning program.
\end{abstract}

This paper acknowledges the input of Dr Carol Kuhlthau (Rutgers University), and Randi Schmidt, (School librarian at Gill St Bernards' School, Gladstone, New Jersey.

\section{Educational Leadership}

The concept of leadership in education is not new. However, a review of the recent educational leadership literature shows a clear shift in focus from authority- or role- or person-centered definitions to those that are cultural and learning-centered, and which explicitly focus on the leading of learning. Lambert asserts that leadership is not about a specific role enveloped in formal authority, rather, it is a "sacred alliance among teaching, learning and leading” (Lambert, 2003, 425), where the emphasis is on educative actions that create complex learning communities and high quality learning outcomes, and a climate of continuous improvement. Oyinlade, Gellhaus \& Darboe (2003) highlight the centrality of learning-oriented leadership qualities, in particular opportunities that focus on student learning and instructional leadership. In a similar vein, Frost \& Durrant (2003) assert that effective leadership in schools is learningcentered leadership which integrates three critical dimensions - collaboration, 
experimenting with practice, and gathering and using evidence - founded on a framework support that involves reflection and critical discourse, planning and strategic action about learning, rather than about the micro-political tensions of professional authority and support (Frost \& Durrant, 2003, 175-176). In essence, educational leadership has three main facets - leadership of students, leadership of operational tasks that move the school towards its learning goals, and leadership through partnerships (Harris, 2003, p. 315).

\section{Leadership and School Librarians}

The concept of educational leadership of school librarians is also not new. It is articulated in terms of concepts such as "school librarian as teacher", "partnerships", "collaborations", "learning outcomes" and "evidence-based practice”. For example, role statements typically state school librarians being:

- “ knowledgeable about current research on teaching and learning and skilled in applying its findings to a variety of situations”

- "committed to the process of collaboration";

- "works closely with individual teachers in the critical areas of designing authentic learning tasks and assessments and integrating the information and communication abilities required to meet subject matter standards";

- "an effective instructor of students";

- "provides leadership ... in bringing an awareness of information issues into collaborative relationships with teachers, administrators, students, and others” (ALA, 1998)

However, such leadership outcomes are seemingly difficult to obtain, and often with disappointing setbacks along the way - budget and staffing cuts, and reduced morale. These outcomes are predicated on a number of key assumptions central to the leadership issue:

- school librarians read research about teaching and learning, and incorporate findings of this research into their instructional practices;

- school librarians do teach, and the teaching-instructional role is a clearly evident phenomena in schools;

- school librarians have a strong and positive collaborative relationship with classroom teachers;

- school librarians clearly articulate their learning leadership in terms of learning outcomes; and

- instructional collaborations result in students achieving higher levels of literacy, reading, learning, problem-solving and technology skills.

Some evidence suggests that these assumptions may not reflect current reality. McClure \& Bishop (1989) and Turner (2002) report that librarian's use of research is low, purportedly because of no time to read research, and because research does not seem to resolve operational concerns. Lau's survey of principals’ perceptions 
of school librarians (Lau, 2002) found that while $80 \%$ of principals believe that the school library and school librarian play a role in the school, only $37 \%$ of principals said that the school librarian made them familiar with current research of library programs and student achievement, and 35\% were made familiar with current research on library programs and reading development. In addition, only $50 \%$ of principals saw their school librarian working in the classroom; indeed, $50 \%$ of principals saw the role of the school librarian to be that of library "caretaker".

While there is research evidence linking the instructional role of school librarians to student achievement, the extent to which this takes place is largely undetermined, though a prevailing perception is that it is low. In a recent study of 154 public school libraries in the US state of Delaware, (100\% of all public school libraries in the state) undertaken by Todd (2005), school librarians were asked to identify the nature of and extent of their instructional involvement in relation to English Language Arts, Social Studies, Science and Mathematics. The following categories were used in this study to identify the level of interaction:

- Cooperation: The teacher and the school librarian may communicate informally about a short term project but work independently;

- Coordination: The teacher and school librarian may meet together to discuss a lesson/unit of study. However, the individual goal setting, learning experience design, teaching, and evaluation are done independently;

- Collaboration: The teacher and school librarian jointly set goals, design learning experiences, teach and evaluate a comprehensive unit of study.

This study found that cooperations were the predominant mode of school librarians' interaction with the school community. The data on the number of coordinations indicate that many school librarians do not engage in any level of formal interaction with teaching faculty in relation to curriculum activities that involve the library. Compared to the number of cooperations and coordinations, the number of collaborations is low. Callison's findings of surveys of school librarians in Indiana shows similar results (2005). $48 \%$ of high schools, $44 \%$ of middle schools and $25 \%$ of elementary schools reported that some teachers and the school librarian collaboratively plan and teach curriculum units. Overall, available data show that the concept of collaboration is more espoused than practised by school librarians.

In the context of educational leadership and school libraries, a critical question is: What constitutes effective shared pedagogy that enables learning outcomes? There is considerable professional literature encouraging school librarians to engage in classroom collaborations, and extensive documentation of exemplars of collaboratively planned units integrating information literacy instruction and curriculum content (see for example recent books by: Loertscher, D., Koechlin, C., \& Zwaan, S., 2004; Bishop, K., 2003; Johnson, M., 2003). However, there has been little teasing out of what constitutes the effective dynamics, processes and strategies of classroom teacher - school librarian collaborations, and articulating the pedagogical 
basis on which effective teaching might be built. In addition, little research has also explored one of the fundamental assumptions underpinning school librarian collaborations, that is, that classroom teachers actually want to collaborate with school librarians, and actually endorse the mutual planning, design, implementation and evaluation of instructional interventions.

This does not mean that principles of what might constitute appropriate pedagogy have not been identified. Donham, Bishop, Kuhlthau, \& Oberg (2001), in documenting the outcomes of the Readers Digest Information Power Project for example implicitly and explicitly identify that effective shared instruction centers on principles of learning as a process of social and personal construction:

- Learners actively searching for meaning and understanding;

- learners constructing deep knowledge and deep understanding rather than passively receiving it;

- learners directly involved and engaged in the discovery of new knowledge;

- learners encountering alternative perspectives and conflicting ideas so that they are able to transform prior knowledge and experience into deep understandings;

- learners transferring new knowledge and skills to new circumstances;

- learners taking ownership and responsibility for their ongoing learning and mastery of curriculum content and skills;

- learners contributing to social well being, the growth of democracy, and the development of a knowledgeable society.

The issue of what constitutes effective shared school librarian-teacher pedagogy raises a myriad of questions: Do teacher-school librarian collaborations actually work, that is, do they enable students to achieve? Do they enable students to achieve better and/or more than traditional instructional methods such as isolated library lessons not linked to curriculum content? What is the nature of the achievement enabled by teacher-school librarian collaborations? If collaborations do work, why is participation in collaborations by school librarians seemingly low? Is collaboration the most appropriate mode of instructional intervention? Should school librarians focus on the individual and small group help rather than class room collaborations? What are the key pedagogical processes that underpin the design and implementation of successful collaborations?

\section{Productive Pedagogy: The Goal of Collaboration}

This paper seeks to understand some of the dynamics of successful teacherschool librarian collaboration, through the lens of the Productive Pedagogy framework developed by Gore, Griffiths, \& Ladwig, (2002). Productive pedagogy is concerned about what is being taught and the quality of learning produced. Based on a series of research studies in Queensland, Australia in 2002, Gore, Griffiths, \& Ladwig sought to develop a model of productive pedagogy that results in high quality student learning 
and improved outcomes. As a framework for quality teaching and learning, it is built around four fundamental principles, namely Intellectual Quality, Relevance, Supportive Environment, and Recognition of Difference. Intellectual quality centers on the development of higher order thinking, depth of knowledge, depth of understanding, ability to engage in substantive conversation, ability to recognize knowledge as problematic, and reading literacy grounded in language, grammar, and technical vocabulary. Relevance is about learning that is linked to students' background knowledge, connected to real life contexts, and where students solve intellectual and real world problems, and integrate knowledge from diverse fields to develop new understandings. A supportive classroom environment is about providing a socially supportive and positive learning environment where students have a say in the pace, direction and outcome of their lessons, where they are engaged and on-task, where performance criteria are made explicit, where diverse cultural backgrounds are brought into play, and where a sense of community, identity and active citizenship are fostered. Recognition of difference refers to the dynamics of learning as an inclusive social and cultural process of community and identity building, where diversity and difference are recognized and integrated as part of the teaching and learning process. The dimensions of productive pedagogy are shown in Table 1.

Table 1: Productive pedagogy dimensions, items and key questions

\begin{tabular}{|l|l|}
\hline \multicolumn{2}{|c|}{ INTELLECTUAL QUALITY } \\
\hline Higher order thinking & Are higher order thinking and critical analysis occurring? \\
\hline Depth of knowledge & $\begin{array}{l}\text { Does the lesson cover central concepts and their complex relations } \\
\text { in any depth, detail or level of specificity? }\end{array}$ \\
\hline $\begin{array}{l}\text { Depth of students' } \\
\text { understanding }\end{array}$ & $\begin{array}{l}\text { Do the work and response of the students provide evidence of } \\
\text { understanding of concepts or ideas? }\end{array}$ \\
\hline Substantive conversation & $\begin{array}{l}\text { Does classroom talk break out of the initiation/ response/ evaluation } \\
\text { pattern and lead to sustained dialogue between students, and } \\
\text { between teachers and students? }\end{array}$ \\
\hline Knowledge as problematic & $\begin{array}{l}\text { Are students critiquing and second-guessing texts, ideas and } \\
\text { knowledge? }\end{array}$ \\
\hline Meta-language & $\begin{array}{l}\text { Are aspects of language, grammar, and technical vocabulary being } \\
\text { foregrounded? }\end{array}$ \\
\hline Knowledge integration & \multicolumn{1}{|c|}{ RELEVANCE } \\
\hline Link to background knowledge & $\begin{array}{l}\text { Does the lesson range across diverse fields, disciplines and } \\
\text { paradigms? }\end{array}$ \\
\hline
\end{tabular}




\begin{tabular}{|c|c|}
\hline $\begin{array}{l}\text { Connection to the world beyond the } \\
\text { classroom }\end{array}$ & $\begin{array}{l}\text { Do lessons and the assigned work have any resemblance or } \\
\text { connection to real life contexts? }\end{array}$ \\
\hline Problem-based curriculum & $\begin{array}{l}\text { Is there a focus on identifying and solving intellectual and/or real- } \\
\text { world problems? }\end{array}$ \\
\hline \multicolumn{2}{|c|}{ SUPPORTIVE CLASSROOM ENVIRONMENT } \\
\hline Students' direction of activities & $\begin{array}{l}\text { Do students have any say in the pace, direction or outcome of the } \\
\text { lesson? }\end{array}$ \\
\hline $\begin{array}{l}\text { Social support for student } \\
\text { achievement }\end{array}$ & Is the classroom a socially supportive, positive environment? \\
\hline Academic Engagement & Are students engaged and on-task? \\
\hline Explicit quality performance criteria & Are criteria for student performance made explicit? \\
\hline Student self-regulation & $\begin{array}{l}\text { Is the direction of student behaviour implicit and self- } \\
\text { regulatory or explicit? }\end{array}$ \\
\hline \multicolumn{2}{|r|}{ RECOGNITION OF DIFFERENCE } \\
\hline $\begin{array}{l}\text { Cultural knowledge values } \\
\text { cultures }\end{array}$ & Are diverse cultural knowledges brought into play? \\
\hline $\begin{array}{l}\text { Public representation of Inclusive } \\
\text { participation }\end{array}$ & $\begin{array}{l}\text { Are deliberate attempts made to increase the participation of } \\
\text { all students of different backgrounds? }\end{array}$ \\
\hline Narrative & Is the teaching principally narrative, or is it expository? \\
\hline $\begin{array}{l}\text { Group identities in learning } \\
\text { community }\end{array}$ & Does teaching build a sense of community and identity? \\
\hline Active Citizenship & Are attempts made to foster active citizenship? \\
\hline
\end{tabular}

\section{Research Questions and Approach}

The productive pedagogy framework provides the lens for examining qualitative data sets derived from a study which focused on the instructional interventions of school librarians in partnership with classroom teachers. This analysis sought to answer the question: do school librarian-teacher collaborations contribute to productive pedagogy, evidenced in intellectual quality, relevance, supportive environment, and recognition of difference? In other words, is the productive pedagogy framework useful for understanding the benefits collaborative instructional process of school librarians and classroom teachers? 


\section{Context and Sample: Gill St Bernards' School, NJ}

The context for this research was the Grade 9 cohort at Gill St Bernards' school, New Jersey. This school is an independent, non-sectarian, college preparatory, elementary and secondary day school. The research involved 43 students (21 girls, 22 boys) undertaking a semester long course "Research Project" which focuses on developing students' critical skills in research, reading, writing and presentation of ideas. Its central feature is the collaboration of 7 teachers and the school librarian to develop complex research skills, strategic and deep information seeking, higher-order information analysis and synthesis to represent new understandings as a result of the research. The instructional program is built around the stages of Kuhlthau's Information Search Process (1984) and a series of carefully planned interventions staged through the instructional program and targeted to the knowledge construction process. The course has two phases: staged instructional intervention culminating in major oral presentation (7 weeks); followed by a guided free-choice research paper (7 weeks) within the theme: "Celebration in Culture" in which students demonstrate mastery of a range of research skills and generate a research paper that demonstrates new knowledge and understanding. This research had several objectives:

- to understand more fully the knowledge construction process of students as they engage in sustained use of a range of information sources;

- to identify patterns of subject access during the search process - through digital, print and personal sources;

- to identify patterns of cognitive intents / goals during the search process;

- to identify the affective-emotional dimensions of engaging in a sustained research project, and

- to identify some of the enablers and barriers to learning though shared instruction.

\section{Data Collection and analysis}

Data were collected from multiple sources. The key data collection instrument was a free generation written protocol administered at three stages in the information search process undertaken by the students (Initiation, Formulation/Focus and Presentation stage of research). Through this protocol we sought to uncover students' base knowledge, perceptions on levels of knowledge and their information seeking and use experience in order to measure changes in the knowledge construction process, and to examine how attitudes and behaviors changed from initiation to presentation. In relation to intellectual quality, the protocol sought to measure students' changes in knowledge about their chosen topic in five ways:

1. Substance of knowledge. The students were asked to state what they know about their topic on an open question "Take some time to think about your research topic. Now write down what you know about this topic.” The students were free to describe topics in their own words. The students completed this question at three 
stages of the project. Conceptual change in the students' knowledge was tracked through classifying the statements students used to describe their topical knowledge. This classification was based on Graesser \& Clark's typology (1984) of statements based on the nature of relationships embedded in them. The statements were:

-Properties:

-Manner:

-Reason:

-Outcome:

-Causality:

-Set Membership:

-Implication:

-Value judgment: statements describing characteristics statements describing processes, styles, actions statements of explanations of how and why statements providing end result statements showing some event causally leads to another statements about class inclusion statements showing predictive relations statements presenting personal position or viewpoint

2. Amount of knowledge. This was measured by a count of the number of statements students used to describe their topical knowledge, as well a as the count of isolated concepts listed.

3. Structure of knowledge. This was based on the way in which the students structured their descriptions of the topic. Students' representations of their knowledge at each stage were examined and coded in terms of their coherence and structural centrality, and were categorized in terms of: (a) discrete ideas, unrelated, or (b) some coherent structure, interrelatedness, or (c) high level of coherence and structural centrality

4. Perceptions of knowledge. The students were asked to indicate their own estimate of their topical knowledge, coded: Nothing, Not Much, Some, Quite a Bit, A Great Deal.

5. Title of knowledge. The students were asked to give a title for their inquiry project, which was considered to reflect the degree of focus/specification of topical knowledge, and an overall conceptualization of their understanding.

In addition, some additional open questions were asked, including what they liked most and least about the research process, and what they had learned doing the research paper.

The second data collection instrument was a structured search log kept by students which recorded all the sources used in constructing their research papers. For each source, students were also asked to list the words they used to look for information; give its citation; give a rating of its usefulness in doing the topic (Very useful; Somewhat useful; Not useful at all); and to establish how they perceived that this information would help them in the knowledge building process. Students were asked to identify the primary cognitive use of the source, based on Todd's Information Intents (1999). The intents were: 
- find some new facts about my topic

- get some background information on my topic

- develop my particular theme more

- get more specific details about facts I already know

- help me find some connections between facts I already have

- correct some ideas I know are wrong

- change my mind about some of my ideas

- help me find out if some ideas I already have are right or wrong

- help me feel stronger about some of my ideas

- see if some guesses I have made are right

- work out if I should stick with my ideas / viewpoint
- sort out some vague ideas I have about the topic

- find some explanations for the ideas I have

- find some different viewpoints about the topic

- clarify things I didn't fully understand before

- help me work out what my viewpoint is on the topic

- help me form an opinion on the topic

- come to some conclusion about these ideas

- work out if I agree or disagree with the ideas I have

- find an argument to back up my ideas

The third data collection instrument was Affective Domain / Next Task Log. This log asked students in each class session to write one sentence about how they were feeling at this stage of their research, and what they saw as their next task. It sought to track the change of feelings associated with information seeking and use. The coding was based on the predominant emotions expressed in Kuhlthau's research on the Information Search Process: confident, disappointed, frustrated, relieved, confused, doubtful, optimistic, satisfied, uncertain, and sure.

\section{Some findings}

\section{Initiation of research task}

The initial representations of students' knowledge of their topics were primarily lists of unrelated concepts, and statements about the topics which listed a number of properties, and language associations (such as alternative expressions or labels). Overall, statements were primarily property ("is a" statements such as "Valentine's Day is red"), manner (describe how something happens, for example "the food is cooked in an earth oven"); and generic descriptions of their topic that showed a surface level of existing knowledge: "the moon glows at night". The initial representations had an average of 4 statements, with an overall range from 0-11 statements, indicating a low level of preexisting knowledge of their topics. Typically the statements were randomly recorded - unstructured, with no clear sequence or 
organization; and with an embedded guess work "I think that..." preceding some statements, indicating some uncertainty or inaccuracy about the statements. When some organizational structure was evident, this was primarily a chronological / historical sequence of facts. Students overall indicated that they knew little about their topics.

Midpoint of research task: focus formulation

The midpoint of the project coincided with students writing and submitting a 100 word abstract to convey the scope and structure of their reports. This task was the culmination of a process where students engaged in building background knowledge of their topics, mapping out the scope and establishing the particular focus of their research. Instructional interventions that facilitated this included: working with appropriate sources to get background information; concept mapping and mind mapping techniques to chart the scope of topics; advanced web searching techniques; strategies for dealing with conflicting information in different sources; as well as personal interviews with class teachers and school librarian to discuss resource needs, barriers to searching, and other issues the students might be experiencing.

The analysis of the students' representations of their knowledge showed an increase in number of propositional statements. The representations ranged from 6 to 34 statements; with the average number of 17 statements. Consistent with a focus on building background knowledge, there was still a strong focus on properties, and representations contained lists of facts describing characteristics; as well as manner statements describing processes, styles, actions. However, there was also a strong presence of reason statements - the provision of explanations of how and why - in relation to factual statements For example, explaining why particular rituals take place within African funerals, linking back to belief systems and social practices. These explanations tended to be elaborative and inclusive rather than descriptive, that is, the students did not just add list of facts, but made explanatory connections that both expanded and integrated isolated facts listed in their initial representations.

Unlike the initial representations, the mid-point representations showed some evidence of organizational structure of ideas - that is, there was some attempt to develop conceptual groupings of facts, rather than randomly listing them. For example, with the chosen topic of "Celebrations in the Cambodian Culture", a student presented groupings around Cambodian New Year, Theravada Buddhism celebrations, Water Festival, and Angkor Festival. Overall, focused themes were starting to shown in their representations, evident by clusters of statements around distinct themes. However, the themes were not often linked into any clear overall coherent and integrated structure.

The analysis of the cognitive intents linked to choice of sources showed that the primary reason for selecting particular sources was getting a bigger picture (building background knowledge) as was expected. Also evident were cognitive strategies related to getting a changed picture, particularly in relation to correcting 
personal misinformation, and getting a clearer picture, that is, finding more information about a particular aspect in order to understand the ideas with greater clarity. $37 \%$ of the students identified some attention to sorting out confusions with facts encountered as they sought to build their background knowledge. This was particularly in relation to conflicting facts discovered during the process of building up background knowledge, for example, different dates for historical events, different foods associated with a particular celebration in a country identified in different sources, different styles of celebrating a particular event. This search for resolution conveys an active engagement with the ideas, rather than a passive accepting of the ideas as they were encountered. Students were actively engaging in information seeking targeted to sorting out their own ideas so that they could move ahead with some certainty. This also suggests that students were actually engaged in construction of their knowledge - the transformation of information rather than the transport of information. It also appears that the task of writing an abstract this point helped students focus on the task. Students indicated that the abstract "kept me to the task", "made me get a big sense of what my overall topic was about"; "gave me a better idea for what I wanted to concentrate on”. They also valued the detailed feedback provided to each student either by the school librarian or the classroom teacher.

\section{Conclusion of Research Task: Submission of Research Paper}

Following the completion of the abstract, and consistent with Kuhlthau's stages of the Information Search Process, students engaged in collecting information specific to their focus, and for constructing their papers. This collection stage was supported by a number of instructional interventions which focused explicitly on the analysis and synthesis of information. This included the compilation of a series of note cards in the students' own words, each recording central ideas with supporting ideas based on the selection of information that the students considered highly pertinent to their topic; the sequencing and grouping of the note cards to assemble ideas into interrelated themes and to build an overall integrated and coherent structure. The initial arrangement of these cards formed the outline of the paper and the first draft. A week after the completion and submission of the paper, students were given the third writing task, asking them to write down again what they knew about their topic. As with previous writing protocols this was done from memory, with no reference to the note cards or working manuscripts.

The analysis of the knowledge representations showed that the average number of statements was 31, with a range from 8 to 63 . This is considerably more than the initial representations. At this stage, there was no evidence of listing of isolated concepts. The representations showed clearer and more precise listing of properties and manner statements, as well as increased use of statements that presented reasons, outcomes, causality, implications, predictive, reflective - all indicative of increased complexity and specificity of topics. Four students showed a decrease in number of statements when compared to the second representation, and on analysis, 
these reflected higher levels of synthesis - that is, the students coalesced increasingly long lists of properties and manners into conceptual categories, and simply presented a more monceptual statement. The final representations also showed higher levels of structural centrality and conceptual coherence to form an integrated whole - that is, an overall integrated and interlinked structure, yet subgroups of ideas that were clearly sequenced. For example, one student's representation on Halloween showed a clear organizational structure around history, central beliefs, processes, and celebration time line. These were interlinked, with attention given to explanations and followed through with implications.

The analysis of the cognitive intents from midpoint to endpoint showed that the cognitive strategies of getting a bigger picture and getting a clearer picture were still important, however, these were associated with delving into the sub-themes of their focused topics, and still getting more facts, clarifying aspects in process of sorting and writing, rather than building more general background knowledge. However, a distinctive feature of the final representations related to getting a position in a picture, that is, developing personal reflections, expressing viewpoints, making positional statements and drawing out comparisons, for example, "I think the religious aspect of the holiday is fascinating. It is interesting because in the US our belief system in religion doesn't seem to be so powerful. In Cambodia it is their life”. In relation to Korean Christmas and men being waited on by wives, one student wrote: "in my culture that would never be thought of, I think it would be thought to be wrong”.

There was also some evidence of clearer focus on their topics through an examination of the titles that students gave to their papers. These tended to move from generic titles, to more narrowly focused topics, and more explicit of the content of their papers. For example: Halloween $\rightarrow$ Halloween in America and Mexico $\rightarrow$ Halloween and the Day of the Dead; Funerals $\rightarrow$ Egyptian Funerals $\rightarrow$ Ancient Egyptian Funerals. A few of the titles presented at the final stage show an interesting development - expressing a final title in both a creative and a narrative way, for example: World Cup $\rightarrow$ World Cup Celebration $\rightarrow$ World Cup soccer and its cult-like following; Woodstock $\rightarrow$ Woodstock and hippies $\rightarrow$ Woodstock: The beginning of the end. Perhaps the students have been able to distance themselves from the topic and look at it from the outside, and more conceptually, which may imply a really inherent understanding of the topic as opposed compiling a product for the sake of completing the task.

\section{Productive Pedagogy: Intellectual Quality}

The representations of students' knowledge at the different stages suggest that the collaborative program of instruction contributed to growth of intellectual quality. The development of knowledge representations from simplistic, superficial and disjointed structures to structures that embedded explanations, causal, predictive 
and reflective statements reflected this change. Particularly noticeable was the analysis and organization of ideas into structured conceptual groupings, which conveyed a sense of knowledge coherence and depth. Knowledge depth was further conveyed in the use of specific terminology associated with the celebrations, and the explanatory details surrounding these. There was substantive evidence that students were using the language specific to the topic domain, not just providing the terms, but clarity of providing descriptions and explanations surrounding these terms. For example, one student's study of the Mexican celebration "Day of the Dead" made increasing use of specific terminology in Spanish, Mexican Day of the Dead (Día de los Muertos), the Aztec month of Miccailhuitontli, presided over by the "Lady of the Dead" (Mictecacihuatl) with clear explanations of the relationship between these two. Another student, whose topic was Kwanza (the African American celebration), showed considerable depth of understanding when discussing the principles of Kujichagulia (Self-Determination).

Given that the knowledge representations in this study were constructed from memory, the students progressed in developing deep understanding of their topics, and this matched the cognitive strategies used when searching for information in a range of sources. Overall, the choice of sources showed increasing complexity and depth. The students' search logs showed that background knowledge was typically built through using encyclopedia references to the particular celebration, or descriptions of the celebration in country-specific books, or information gathered from country, travel or festival web sites. There was also some use made of compendiums which listed and briefly described numerous festivals and celebrations around the world. However, as students progressed, there was some change in the nature of the sources used, particularly to print and electronic sources that dealt solely with the particular celebration as a basis for building deeper knowledge.

In terms of the intellectual quality dimension of substantive conversation, the overall fluency and fluidity of the written representations indicate ability to substantially communicate in writing about their topical knowledge. Students aslo engaged in a number of interviews with their classroom teacher and school librarian as they progressed with their research. Their written comments showed that they valued the opportunity to talk about their projects - both in terms of substantive content, and the research process. They saw that these conversations helped to clarify the direction and scope of their research, and helped them determine what were the most pertinent ideas for their topics. One student wrote: "I enjoyed the actual research and found it helpful to talk about my topic to the librarian, which was easy to do because the research helped me know the stuff really well". Others commented: "We knew we were expected to talk about our topics with our teachers, so it makes you concentrate on the topic and know the details", and "If I had to explain it to someone and give good details, I could”.

There was some evidence that students could deal with conflicting facts or viewpoints. For example, a student encountered different customs about St Patrick's 
Day celebration, and it was not until she identified the origin of the information sources (USA and Ireland) that she was able to resolve this confusion. Another student exploring Kwanza encountered different descriptions of the historical origins of this celebration, and in his second writing task acknowledged that she was "finally enjoying reading the information from the different books; it was interesting to get different ideas once I learned how to handle them - reading is the easiest part. Putting the whole thing together was the hardest part". Students showed evidence of constructing arguments and explanations in relation to conflicting aspects of topics. For example, one student acknowledged different sources that showed different descriptions of Norwegian Christmas celebrations (encyclopedia versus book focusing on Scandinavian celebrations), and said that "learning to get the right facts was hard to do”.

\section{Productive Pedagogy: Supportive Classroom Environment}

Students' responses to the open questions shed light on aspects of the learning process and learning environment they valued during the program. An analysis of the feelings experienced by students showed that the research was somewhat of an emotional rollercoaster journey. There was a very distinctive ebb and flow of emotions which followed the deadlines that were crafted by the teachers and the librarian to guide the students effectively through the research process. Students had to meet six separate deadlines in the process: a proposal identifying their focused topic, note cards identifying central ideas for constructing their paper, bibliography, outline, rough draft, and final paper. In addition, at the completion of the paper, student has to write an abstract demonstrating their ability to succinctly summarize their research.

At the commencement of the research, the expressions of feelings varied from a state of confidence about the task, to hesitation and uncertainty, for example; "pretty good”, “a little nervous”, “very scared”, “worried”, "freaking out”, “in pain”. There was an increase in optimism and confidence as they identified a general topic and begin to investigate sources for relevant information to build their background knowledge. As deadlines approached, particularly the abstract and note cards, most students reported decrease in confidence, and increase in frustration and uncertainty. As they passed these deadlines and had feedback on the scope and structure of their papers, they typically began a slow climb back to being optimistic and confident, although some frustrations with sources and deadlines and achieving focus clearly continued to surface. It was at this point - the point where complex information processing and knowledge construction takes place - analysis, synthesis, dealing with conflict, structuring arguments, sequencing ideas - that there was an increase in negative emotions - with "stress", “pressure” and "brain strain” being reported. This increased as deadlines for the outline and draft approached. At the time of submission of the paper, students expressed relief and confidence (because of level of research done), with a widespread acknowledgement that it was "hard work" but worthwhile, 
because "I learned heaps". This roller coaster of emotions was recognized by the teaching team, and interventions implemented to support students.

Individual meetings and feedback sessions encouraged students to talk about their feelings, and students could provide examples of note cards or draft abstracts for critique. Students clearly valued the supportive environment, particularly shown in opportunities for dialogue, feedback, encouragement and enabling them to deal with the emotional and intellectual demands of the task. The supportive environment was evident in other ways: the instructional interventions explicitly targeted to the skills requirements of the project, for example, the class activities that helped them impose structure on their ideas and transform them into personal understanding, particularly through the presentation of abstract, notecards and outline: "This was a very exhausting process, but none the less, it was all worth it. I finally learned how to write a proper paper, not only for research, but any paper in general. I got to spend quality time with my teacher and librarian. The three things I enjoyed in writing and research are reading the books, making an outline, and LEARNING. I definitely learned a lot both about my interesting topic, and the research to make it happen”. One student commented: "A six page research paper scared ... me, but with the help I got while doing the project, I knew I could do it. This project opened me to new ideas, and how to write my own ideas and thoughts based on them. I enjoyed recording my thoughts because I like to express how I am feeling during the process. This allowed my teachers and librarians to know my thinking throughout the course and to guide me better". Another student said that "my teacher and librarian were on the same page".

Students also valued the instructional intervention that modeled the intellectual scaffolds for successfully completing the task. One student commented: "I have learned many things about the research process after completing this project. The tracking sheets showed me that organization is important when researching. It helped me manage the time and showed me just how indepth my knowledge became. Another good thing was that there was always help available from the teachers and librarians”. The students did not feel abandoned during the research process, particularly at the writing stage, when complex thinking process are required. For example, one student said: "I knew what to do all along the way, and when I got stuck, I could get help right away. I didn't get the notecards at first, but I was shown how to move them around in interesting ways”.

Students also valued that the whole process was presented to them with stages and milestones to be reached. They were provided with guidelines which encompassed the whole learning process, clear expectations of tasks to be submitted, criteria for assessment, dates, and feedback and support mechanisms. Some students acknowledged that the expectations were high, as one student commented: "I wondered if I would make it, but I did! YEAH. I liked being able to do it with the deadlines and get to know where I was going"; and "keeping up with the deadlines was stressful, but they helped me get it done”. The specification of stages, expectations and criteria provided direction for the students. In the analysis of the 
Affective Domain / Next Task Logs, there was some evidence to suggest that students were making decisions about their next steps on the basis of the stages and deadlines spelled out to them, for example "I must begin my notecards because they are due in a week”. By providing direction and regulation, this appeared to keep students on task and engaged, as well as able to manage all of the complexities of the task, which initially were quite daunting to the students: "I learned to follow a set plan and be organized”

\section{Productive Pedagogy: Relevance}

Two aspects of relevance, particularly links to students' background knowledge and connection to the world beyond the classroom, came through in the study. When students were asked to identify how much they new of the topic, there was a definite and clear progression from very little to a great deal, with links made to low levels of initial knowledge. Four categories emerged in the changes to the amount of knowledge: (1) the students stated that they know "heaps" more; (2) they knew lots more, and expressed surprise at the breadth and depth of their current knowledge; (3) they knew lots more, but felt they still could learn more; and (4) they knew lots, but mentioned some dissatisfaction about not knowing enough.

Students were given free choice of topic within the theme "Celebration of Culture". When asked at the initiation of the research why they had chosen their particular topic, they cited personal experiences (participating in a particular celebration), personal connections (know someone who participates), knowledge of intriguing facts or aspects about topic, or curiosity (typically based on having read or viewed something), as the primary reasons for selecting their particular topic. For example, in relation to "birthdays", a student wrote "I enjoy exploring symbols and understanding the meaning of these symbols, such as a birthday cake"; in relation to choosing the Chinese Dragon Festival, one student wrote: "I remember the stories my father told me about that". These reasons primarily reflect connections made to personal real life contexts, and these findings underscore the importance of embedding learning in meaningful life contexts. However, as students progressed, there was a change in the expressions of interest, initially coming from outside the research (that is, the personal connection) to interests generated by the project itself. As students learned more about their topic, the specific new knowledge they acquired generated curiosity and motivation, encouraging them to dig deeper into their topic. For example: from "Soccer is my favorite sport. I will get up during the night to watch matches" to "I find it totally amazing that 5 billion watched the 2002 game and want to find out some more about that".

Students also identified the long-term relevance of their learning. When asked what had they learned in this project, the students identified both increase in content knowledge, as well as acquiring a range of useful skills that would help them further with their schooling: "help me through papers in high school, college and life in general"; "learned the basics of writing a more professional research paper for my 
senior year"; "extensive and organized research is essential for the writing of a good paper. I learned to use information effectively and will do well in future papers”.

\section{Productive Pedagogy: Recognition of Difference}

The dimension of productive pedagogy focusing on recognition of difference is supported in some of the data. Of course, the theme "celebration of culture" provide an opportunity to explore a range of international cultural celebrations, and only $19 \%$ of students chose USA centered celebrations: "I want to research something in another country; I want to go and see how they live. I know little about Asia so it would be good to learn"; "In Mexico, I find the idea of picnics in cemeteries very interesting - and contrary to the popular view here of cemeteries" and "I loved expanding my view of the world and this helped" In exploring a diverse range of celebrations, some students made comparisons to events, values, circumstances and behaviors in the USA.

Perhaps the strongest evidence in relation to recognition of difference as a dimension of productive pedagogy was provided in the comments made by some students in relation to accommodation of individual needs. These students perceived that they got individualized help on their resource needs, searching concerns and dealing with individual things that cropped up unexpectedly, such as failed discs or printing problems: "it was very frustrating when you work really hard to find a book or a website and it is worth nothing and has no useful information. They [librarian and classroom teachers] seemed to spot it right away and make suggestions which got you going again"; "I liked coming into the library and they always seemed to be interested in how I was doing as if I was the only one doing it”.

\section{Conclusion}

This analysis sought to shed some light on whether school librarian-teacher collaborations contribute to productive pedagogy, evidenced in intellectual quality, relevance, supportive environment, and recognition of difference. It is evident in this case study that the carefully planned collaboration, where students were guided in a closely supervised way through the process of inquiry gradually lead to substantial learning outcomes, evidenced in terms of deep knowledge and deep understanding of their topics, in their ability to apply complex thinking skills to transform information into knowledge, and to demonstrate their knowing This did not happen by the mere fact of collaboration. A collaboration in and of itself may not necessarily result in learning. It called for carefully structuring the learning environment in ways that enabled students to be intellectually productive, that gave them choice in the scope and direction of their learning, supported them in many ways, including instructional interventions targeted to the knowledge construction process. It embedded into the instructional design a range of mechanisms for supporting students throughout their inquiry, dealing with affective, cognitive and behavioral demands of the research task. 
This was clearly modeled on the Information Search Process, which provided an instructional framework for guiding the students, and ownership of the learning was turned over to the students, with specific interventions determined by the stage of the search process, the affective, cognitive and behavioral needs of the learners, and the curriculum standards and goals to be achieved.

The Productive Pedagogy framework elaborated here provides a useful set of questions to guide the planning process for effective learning in collaborative inquiry units. Its value comes through its focus not only on shaping the learning environment and building a culture of meaningful, relevant learning for the students, but also thinking about and planning for the learning outcomes to be achieved in terms of deep knowledge and deep understanding of the curriculum topics being studied. This is the educational leadership challenge for all school librarians. It is eloquently summed up by the poet Edna St Vincent Millay, who provides a sense of the vision, the window of opportunity for all school librarians:

"Upon this gifted age, in its dark hour Rains from the sky a meteoric shower Of facts, they lie unquestioned, uncombined. Wisdom enough to leech us of our ill Is daily spun, but there exists no loom To weave it into fabric. 


\section{References}

American Association of School Librarians \& Association for Educational Communications and Technology. (1998). Information Power: Building Partnerships for Learning. Chicago: American Library Association.

Bishop, K. (2003) Connecting Libraries with Classrooms: The Curricular Roles of the Media Specialist. Worthington, OH: Linworth Press, 2003.

Callison, D. (2005) Data from Indiana School Library Media Programs in 2004. Available at: http://www.ilfonline.org/Units/Associations/aime/Data/navigate.htm

Day, C. (2004). The passion of successful leadership. School Leadership \& Management, 24(4), 425-437.

Donham, J. K., Bishop, K., Kuhlthau, C, \& Oberg, D. (2001). Inquiry based learning: Lessons from Library Power. Worthington, OH: Linworth.

Frost, D. \& Durrant, J. (2003) Teacher Leadership: rationale, strategy and impact. School Leadership \& Management, 23(2), 173-186.

Gore, J., Griffiths, T., \& Ladwig, J. (2002). Productive Pedagogy as a Framework for Teacher Education: Towards Better Teaching. Newcastle: Faculty of Education, University of Newcastle. Available at: http://www.aare.edu.au/01pap/gor01501.htm

Graesser, A. \& Clark, L. (1985). Structures and procedures of implicit knowledge. Norwood, N.J.: Ablex.

Harada, V. \& Yoshina, J. (2004). Inquiry Learning Through Librarian-Teacher Partnerships. Worthington, OH: Linworth Press.

Harris, A. (2003). School Teacher Leadership as Distributed Leadership: heresy, fantasy or possibility? Leadership \& Management, 23(3), 313-324

Johnson, M. (2003). Primary Sources in the Library: A Collaboration Guide for Library Media Specialists. Worthington, $\mathrm{OH}$ : Linworth Press.

Loertscher, D., Koechlin, C., \& Zwaan, S. Ban Those Bird Units! 15 Models for Teaching and Learning in Information-rich and Technology-rich Environments. Hi Willow Research and Publishing, 2004 
Kuhlthau, C. C. (2004). Seeking meaning: A process approach to library and information services. $2^{\text {nd }}$ edition. Westport, CT: Libraries Unlimited.

Lambert, L. (2003). Leadership redefined: an evocative context for teacher leadership. School Leadership \& Management, 23(4), 421-430.

Lau, D. (2002). What does you boss think about you? School Library Journal, 48(9), 5255.

McLure, C. \& Bishop, A. (1989). The status of research in Library and Information Science. College \& Research Libraries, 40, 127-143.

Oyinlade, A., Gellhaus, M, \& Darboe, K. (2003). Essential Behavioral Qualities for Effective Leadership in Schools for Students Who Are Visually Impaired: A National Study. Journal of Visual Impairment \& Blindness, 97(7), 389-420.

Todd, R. (1999). Utilization of heroin information by adolescent girls in Australia: a cognitive analysis. Journal of the American Society for Information Science, 50(1), 10-23.

Todd, R. (2005). Report of the Delaware School Library Survey2004. CISSL Unpublished report.

Turner, K. (2002). Do information professionals use research published in LIS journals? Paper presented at the $68^{\text {th }}$ IFLA Council and General Conference August 18-24 2002. Available at: http://www.ifla.org/IV/ifla68/papers/009-118e.pdf

\section{Author Note}

Ross $\mathbf{J}$ Todd is Associate Professor in the School of Communication, Information and Library Studies at Rutgers, the State University of New Jersey. He is Director of Research of the Center for International Scholarship in School Libraries (CISSL) at Rutgers. He teaches courses in Human Information Behavior, Research Methods, as well as courses in the School Library specialization. His current research focuses on the cognitive dynamics of adolescent information seeking and utilization; how learners build personal understanding in complex information environments; understanding how school libraries contribute to student learning outcomes, and developing approaches to evidence-based practice for school librarians. 
Reproduced with permission of the copyright owner. Further reproduction prohibited without permission. 